\title{
MEMÓRIAS DE LUTA: BRASILEIROS NO EXTERIOR (1993-2010)
}

\author{
Memories of struggles: Brazilian abroad (1993-2010)
}

\author{
Bela Feldman-Bianco ${ }^{7}$
}

\begin{abstract}
Resumo. Neste ensaio, o meu intuito é expor as relações entre as mobilizações de transmigrantes brasileiros em Lisboa contra as políticas restritivas de imigração da era Schengen, a constituição de uma Comunidade de Brasileiros no Exterior em prol de seus direitos de cidadania no Brasil e a formulação de políticas do Estado brasileiro dirigidas à sua diáspora, durante a era Lula (2003-2010). Desse ângulo, examino essas mobilizações desde o primeiro caso de extradição de brasileiros ocorrido no aeroporto de Lisboa em inícios de 1993 e a eclosão de conflitos diplomáticos entre Brasil e Portugal. Analiso seus desdobramentos em contextos diversos através de um período de 17 anos, discernindo, assim, o processo de formação e globalização de um movimento social dos Brasileiros no Exterior e suas conexões com a luta pelos direitos dos imigrantes no Brasil. Argumento que o deslanche desse movimento social global desde Lisboa revitalizou e expandiu a mobilização em prol dos imigrantes no Brasil, inclusive a luta por uma nova legislação migratória baseada em direitos humanos.
\end{abstract}

Palavras-chave: movimento social, brasileiros no exterior, direitos humanos, políticas migratória, criminalização de imigrantes

\begin{abstract}
In this paper, I expose the relations between the mobilization of Brazilian transmigrants in Lisbon against the Schengen restrictive immigration policies in Portugal, the constitution of a Community of Brazilians Abroad demanding citizenship rights in Brazil and the formulation of public policies by the Brazilian state on behalf of its diasporic population during the Lula era (2003-2010). From this perspective, I examine the formation of this social movement since the first deportation case of Brazilians in the Lisbon airport in 1993. I disclose the subsequent mobilizations in diverse places and contexts throughout a period of 17 years tracing, thus, the globalization process of this social movement as well its connections with the struggles for the immigrant rights in Brazil. I suggest that the launching of this global
\end{abstract}

1 Professora colaboradora do Programa de Pós-Graduação em Antropologia Social da UNICAMP. Campinas, SP, Brasil. 
social movement in Lisbon has revitalized and expanded the mobilizations in favor of immigrants in Brazil, including the struggles for a new legislation law based on human rights.

Keywords: social movements, Brazilian abroad, human rights, migration policies, criminalization of immigrants.

Neste ensaio², o meu intuito é expor as relações entre a constituição de uma Comunidade de Brasileiros no Exterior, as mobilizações de transmigrantes do Brasil em prol de seus direitos de cidadania e a formulação de políticas pelo Estado brasileiro num período marcado pela redemocratização do país. Desse ângulo, examino a formação desse movimento social e os correlatos processos de construção e desconstrução de categorias e representações utilizadas na identificação e auto identificação de migrantes, desde o primeiro caso de extradição de brasileiros ocorrido no aeroporto de Lisboa em inícios de 1993. Analiso os desdobramentos desse movimento em contextos diversos através de um período de 17 anos, discernindo, assim, seu processo de globalização e suas conexões com a luta pelos direitos dos imigrantes no Brasil. Privilegio, como fio condutor da narrativa, as mobilizações da Casa do Brasil de Lisboa, devido à importância dessa associação e de suas práticas transnacionais na luta pelos direitos dos migrantes tanto no cenário europeu quanto brasileiro, especialmente entre 1993 e 2010.

Dessa perspectiva, delineio as lutas de lideranças transmigrantes radicadas em Lisboa por seus direitos de cidadania em Portugal pós-colonial e, nesse contexto, os processos de constituição de uma Comunidade de Brasileiros no Exterior voltada à demanda de políticas públicas dirigidas às populações desterritorializadas do Brasil. Suas (duplas) mobilizações enquanto imigrantes em Lisboa e emigrantes do Brasil, no contexto do ingresso de Portugal na Comunidade Econômica Europeia e subsequente adesão às políticas restritivas do Tratado Schengen, traz à tona indagações sobre a relação entre migrações, nações e nacionalismo, bem como entre movimentos sociais e Estados de origem e de radicação de migrantes transnacionais na atual conjuntura global. Foi necessário, portanto, levar em conta as reelaborações das ambíguas relações coloniais entre Portugal e Brasil face aos seus reescalonamentos diferenciados na economia política global, no bojo da crise do capitalismo das décadas de 1980 e 1990. Consequentemente, tornou-se crucial examinar os espaços de manobra e negociação utilizados por lideranças transmigrantes formadas por brasileiros, luso-brasileiros e até portugueses que haviam emigrado para o Brasil e retornado à Portugal num cenário de recorrentes jogos de semelhanças e diferenças culturais entre os dois países. 2 Esse artigo é uma síntese atualizada de FELDMAN-BIANCO, Bela. Caminos de ciudadanía:
Emigración, Movilizaciones sociales y políticas del Estado brasilero. 
Desse posicionamento, argumento que as mobilizações iniciadas na antiga metrópole imperial por transmigrantes brasileiros e de outras ex-colônias portuguesas contra as políticas restritivas do Estado pós-colonial português foram decisivas para a formação de um movimento social de emigrantes brasileiros por seus direitos no Brasil. Além de explicitar a importância das articulações realizadas desde Lisboa, indico o papel crucial desempenhado por vários protagonistas para a globalização desse movimento social, como transmigrantes, Igreja Católica, estudiosos e ativistas da questão migratória, núcleos do Partido dos Trabalhadores no exterior e autoridades governamentais. Nesse âmbito, revelo como um conjunto de documentos reivindicativos, lançados em colóquios realizados em diferentes momentos e espaços desse movimento social, se transformou em pauta de uma agenda interministerial do Estado brasileiro, influenciando a formulação de políticas públicas destinadas aos assim chamados Brasileiros no Exterior, durante a era Lula. Sugiro, ainda, que essas lutas dos transmigrantes brasileiros revitalizaram e expandiram as mobilizações em prol dos imigrantes no Brasil, incluindo lutas pela substituição do retrogrado Estatuto do Estrangeiro de 1980 baseado em segurança nacional, por uma nova legislação ancorada em direitos humanos.

\section{Novas concepções de nação, políticas de imigração e as construções sociais dos imigrantes na era pós-Schengen}

O Brasil, historicamente país de imigração, se tornou também exportador de migrantes mundo afora, atraindo ao mesmo tempo novos imigrantes do continente sul-americano, além de chineses e africanos e, mais recentemente, haitianos e refugiados da Síria. Esse reposicionamento na economia política global chama a atenção para a interligação entre emigração e imigração numa conjuntura de internacionalização da economia, flexibilização do capital e do trabalho, e predominância de políticas e ideologias neoliberais, trazendo à tona dois processos simultâneos e aparentemente contraditórios. De um lado, surgem, desde meados da década de 1980, novas concepções de nação e nacionalismo que incorporam, seja por legislação ou por retórica, suas populações emigrantes tanto por parte de ex-metrópoles imperiais quanto de ex-colônias. No caso da União Europeia, a remodelagem das nações, incluindo a ampliação de direitos de nacionalidade e cidadania foi realizada predominantemente através do Jus sanguinis (ou direitos às raízes), com vistas ao controle da circulação no espaço comunitário europeu. Antigos emigrantes e descendentes passaram a ser identificados como cidadãos no exterior e cidadãos comunitários em contraposição aos extracomunitários, delimitando assim os direitos de entrada e circulação no espaço comunitário europeu. Por outro lado, desde o Tratado de Schengen, legislações imigratórias europeias, cada vez mais restritivas, fundamentadas em políticas de governança tecnocrata de securitização, criminalizam os cidadãos 
extracomunitários, sobretudo aqueles em situação indocumentada, criando um virtual apartheid europeu³. Já, nos Estados Unidos, país de imigrantes e cujas leis oscilaram entre abertura e fechamento dos portões de imigração de acordo com os fluxos da economia, a associação entre migrantes e terrorismo inicia-se em 1996, com a bomba de Oklahoma e se intensifica no pós-setembro de 2001, com a assim chamada Guerra contra o Terror. Se as legislações migratórias de diferentes países historicamente diferenciaram migrantes desejáveis dos indesejáveis, desde a década de 1990 passou a prevalecer nos países centrais a equação entre migração terrorismo e tráfico, legitimando, assim, a produção da ilegalidade. Essas legislações restritivas estão em consonância com reconstruções da noção de tráfico de pessoas, pela ONU (Protocolo de Palermo) e seus diferentes organismos multilaterais. Em consequência, imigrantes passaram a ser representados e percebidos como perigo, ameaça e obstáculo aos estados nacionais. Além do mais, categorias duais têm sido empregadas para classificá-los, identificá-los e diferenciá-los, de forma discriminatória, enquanto legais ou ilegais, regulares ou irregulares, implicando em processos de (parcial) incorporação para os migrantes em situação documentada e exclusão, clandestinidade e invisibilidade para aqueles em situação indocumentada.

Existe, portanto, uma relação intrínseca entre essas políticas restritivas que, desde o Tratado de Schengen, têm resultado em deportações sistemáticas, mortes e até assassinatos de imigrantes em situação indocumentada e as mobilizações de brasileiros que vivem e trabalham na Europa e nos Estados Unidos em prol do reconhecimento de seus direitos de cidadania no Brasil. Num Portugal pós-colonial que havia se tornado também país de imigração - e à época atraindo predominantemente seus antigos sujeitos coloniais -, a adesão à Schengen em 1991 e a promulgação de uma Nova Lei de Estrangeiros em finais de 1992, levaram a um aumento de fiscalização nos aeroportos portugueses e, logo no início de 1993, às deportações de brasileiros e cabo-verdianos. Constituindo-se no primeiro caso de extradição de um grupo de brasileiros na era Schengen, essas deportações revelaram os impasses latentes criados por essa nova "Lei dos Estrangeiros" especialmente nas relações com o Brasil, devido à existência de Tratado Bilateral de Igualdade de Direitos entre os dois países. Firmado em 1972, por ocasião das guerras coloniais, esse tratado possibilitou que o Estado colonial português deslocasse para o Brasil uma boa parcela dos contingentes de "retornados" da África.

O rompimento do Tratado de Igualdade de Direitos entre Portugal e Brasil ocasionou conflitos diplomáticos entre os dois países, num período em que a migração transnacional de brasileiros era novel e a diplomacia brasileira parecia ainda desconhecer as implicações da nova legislação relacionada à circulação

BALIBAR, Étienne. We, the people of Europe. 
de pessoas no espaço comunitário europeu. Convertidos em um "drama familiar", esses conflitos diplomáticos acionaram jogos identitários baseados na produção de diferenças e semelhanças culturais sinalizando fronteiras culturais ambíguas. Nesse cenário, retóricas de irmandade, fundamentadas em similaridades de língua, cultura e história entre antigos colonizados e ex-colonizados possibilitaram espaços de manobra, tanto nas negociações bilaterais entre Brasil e Portugal quanto na mobilização de imigrantes das ex-colônias portuguesas em África que, naquela época, constituíam a maioria da população migrante em Portugal ${ }^{4}$.

Naquela conjuntura histórica, a Casa do Brasil de Lisboa (CBL) se tornou protagonista importante na luta pelos direitos dos imigrantes em Portugal. Fundada em 1992 por brasileiros, luso-descendentes e portugueses com longa vivência no Brasil, em sua maioria profissionais liberais, alguns dos quais antigos exilados contando com influentes redes transnacionais, a CBL desde o início dispôs de acesso aos centros de poder em ambos os países. Suas lideranças começaram a se reunir em Lisboa durante a campanha para as eleições presidenciais brasileiras de 1989, quando Lula e sua delegação estabeleceram contato com petistas e simpatizantes radicados na ex-metrópole imperial. Posteriormente, em 1992, em decorrência das mobilizações em favor do "impeachment" de Collor, essas lideranças criaram a Casa do Brasil de Lisboa. No ano seguinte, algumas delas também constituíram um núcleo do PT em Lisboa, indicando a sua contínua participação na política institucional brasileira, bem como a estratégia desse partido em favorecer a criação de núcleos no exterior.

Reconhecida legalmente como associação de imigrantes, a CBL foi definida por um de seus fundadores, como "uma associação civil da sociedade portuguesa, ligada aos imigrantes e às coisas do Brasil e dos brasileiros, composta por amigos do Brasil e dos brasileiros, tenham a nacionalidade que tiverem". Ao mesmo tempo em que promovia a cultura brasileira e a brasilidade - com suas noites de música brasileira e seus cursos de samba, forró e maracatu-, procurava dar "bastante visibilidade às dificuldades e reivindicações dos brasileiros" ${ }^{5}$. Se caracterizou, assim, por uma dupla construção social que abarca tanto "as lutas pelos direitos dos cidadãos e a afirmação da prática da cidadania dos (e pelos) imigrantes em Portugal (...)", como "a luta dos emigrantes brasileiros pelo reconhecimento de seus direitos e problemas específicos por parte da sociedade, dos governos e dos vários órgãos do Estado brasileiro".

Devido às suas redes de relações e acesso aos centros de poder em Portugal e no Brasil, a CBL se tornou um importante protagonista nos movimentos sociais

\footnotetext{
${ }_{4}$ Ver Feldman-Bianco (op. cit.) para uma análise desses conflitos diplomáticos entre Portugal e Brasil e as mobilizações de transmigrantes brasileiros e de ex-colônias portuguesas em prol de seus direitos no Brasil.

5 BEHR, Gustavo. Entre filas, Conselhos e maracatus.
} 
contra as políticas migratórias europeias, não só no âmbito de Lisboa, mas, também, ao nível nacional e supranacional. Desde a extradição do primeiro grupo de brasileiros no aeroporto de Portela, passou a reivindicar, junto aos poderes públicos do Brasil e de Portugal, a continuidade do Tratado de Igualdade de Direitos Recíprocos de 1972, como forma de garantir direitos recíprocos entre portugueses do Brasil e brasileiros de Portugal. Suas ações e estratégias influenciaram uma discriminação positiva em relação aos imigrantes brasileiros e outras ex-colônias lusas no desenho das políticas públicas e legislações portuguesas que culminaram no Acordo Lula de 2003. Suas mobilizações foram, ao mesmo tempo, fundamentais para a formação de um movimento social global em prol de políticas públicas do Brasil dirigidas à Comunidade de Brasileiros no Exterior que se entrosou e fortaleceu as lutas em favor dos direitos dos imigrantes no Brasil.

\section{A CBL e a mobilização a favor dos direitos de emigrantes brasileiros no Brasil}

Em contraste com outros países da América Latina e do Caribe com longa história de emigração, cujos governos instituíram políticas de inclusão de suas populações desterritorializadas ainda na década de 1980, as primeiras ações do governo brasileiro se iniciaram somente em 1997, durante a presidência de Fernando Henrique Cardoso, com a formação de Conselhos das Comunidades junto aos consulados. Convidada a fazer parte do Conselho em Lisboa, a CBL se mobilizou rapidamente. Já em outubro daquele ano, realizou o I Seminário Internacional sobre Emigração Brasileira, com o apoio do Consulado de Lisboa e do Centro de Estudos de Migrações Internacionais (CEMI) da UNICAMP. Reunindo pela primeira vez lideranças transmigrantes de alguns países - como Suíça, Canadá e Estados Unidos, representantes do Ministério de Relações Exteriores (MRE), Congresso Nacional, Comissão Nacional de População e Desenvolvimento (CNPD) e da academia, além de organizações portuguesas -, esse seminário foi o marco inicial da mobilização em prol dos Brasileiros no Exterior, categoria construída para ressaltar os direitos de cidadania dos que escolheram viver fora do Brasil. Numa ocasião em que a academia estava começando a pesquisar a emigração brasileira e o MRE tinha pouco conhecimento sobre a questão migratória, esse evento desempenhou papel importante para conscientizar pesquisadores e representantes do poder público sobre a imprescindibilidade de políticas públicas para essas populações desterritorializadas do Brasil não somente na esfera dos direitos humanos, mas como parte da política externa brasileira.

Como consequência direta desse evento, um grupo de trabalho sobre migrações internacionais foi criado no âmbito da CNPD, que se responsabilizou pelo seminário internacional Migrações Internacionais: 
contribuições para políticas - estrangeiros no Brasil e brasileiros no exterior, realizado no Itamaraty (MRE) em dezembro de 2001 com a participação de acadêmicos e representantes de vários ministérios ${ }^{6}$. Mesmo não contando com a representação dos "brasileiros no exterior", esse evento foi importante por inserir debates simultâneos sobre emigração e imigração e, nesse sentido, a demanda por uma nova legislação migratória, em diferentes esferas do poder público do Brasil.

Seguiu-se o I Encontro Ibérico da Comunidade de Brasileiros no Exterior, como parte do Projeto Brasileiros no Exterior, lançado pela Procuradoria Regional dos Direitos do Cidadão do Distrito Federal. Esse projeto resultou de investigação instaurada em Brasília no âmbito da Sub Procuradoria dos Direitos do Cidadão dirigida a apurar as causas de um acidente ocorrido com vários brasileiros em uma cidade mexicana próxima à fronteira com os Estados Unidos. Porém, à medida em que os desenvolvimentos desse inquérito revelaram a situação crítica da comunidade de brasileiros no exterior, decidiu-se planejar um evento de caráter propositivo a fim de se obter maiores informações e dar visibilidade aos brasileiros que migraram para o exterior ${ }^{7}$. Realizado em Lisboa, em maio de 2002, esse encontro contou com o apoio organizacional da CBL e a colaboração de vários órgãos da Igreja Católica. Nesse âmbito, foi criado um grupo de trabalho responsável pela elaboração de propostas de políticas públicas dirigidas aos emigrantes. A destacada atuação do Instituto de Migrações e Direitos Humanos (IMDH) indicou a importância da Igreja Católica na globalização desse movimento social.

Assim como o seminário realizado em 1997, esse I Encontro Ibérico da Comunidade de Brasileiros no Exterior contou com a participação e interlocução com autoridades governamentais portuguesas e pessoas que trabalham diretamente com imigrantes, além de representantes de associações imigrantes de outras nacionalidades. Resultou num conjunto de reivindicações e propostas conhecido como o Documento de Lisboa, que se tornou principal referência para a mobilização dos brasileiros na Europa e autoridades governamentais do Brasil, assim como nas lutas em prol dos imigrantes no Brasil.

Ainda em 2002, a cobrança feita pela CBL aos candidatos à Presidência da República em relação às comunidades de brasileiros no exterior, deu origem à carta de Lula aos Brasileiros que Vivem Longe de Casa. Nessa carta, amplamente divulgada nas comunidades migrantes pelos núcleos do PT que

\footnotetext{
Tanto o grupo de trabalho quanto o seminário foram idealizados pela demógrafa Elza Berquó, então à frente do CNPD, que havia participado do I Seminário Internacional de Emigração Brasileira. Os textos apresentados no simpósio foram publicados em Migrações Internacionais: Contribuições para Políticas, organizado por Mary Garcia Castro e distribuído gratuitamente pelo CNPD/IPEA.

MILESI, Rosita, FANTAZZINI, Orlando. "Cidadãs e Cidadãos Brasileiros no Exterior: O Documento de Lisboa, a Carta de Boston e o Documento de Bruxelas".
} 
proliferaram no exterior, Lula projeta a sua própria experiência como migrante e se compromete a estabelecer políticas para os emigrantes do Brasi ${ }^{8}$.

Em 2003, depois da sua posse como Presidente do Brasil, em visita a Lisboa, em meio ao estabelecimento de parcerias bilaterais luso-brasileiras no âmbito do Mercosul e União Europeia, Lula firmou um tratado sobre contratos de trabalho recíprocos, conhecido como Acordo Lula. Visando beneficiar imigrantes em situação indocumentada do Brasil em Portugal e de Portugal no Brasil, esse acordo foi, em grande parte, resultado de demandas e negociações pragmáticas da CBL junto aos representantes do poder público brasileiro, caracterizadas por uma política do possível. Fundamentou-se no Tratado de Amizade, Cooperação e Consulta entre Brasil e Portugal consolidado em 22 de abril de 2000, durante as celebrações dos "500 anos" de Brasil, que substituiu aquele originalmente estabelecido em 1972. Incluiu um modelo de legalização de imigrantes brasileiros residentes em Portugal através de contrato de trabalho com o intuito de "concretizar o regime processual de atribuição e registro do estatuto de igualdade aos cidadãos brasileiros residentes em Portugal". Por tanto, permaneceu vinculado à lei de imigração portuguesa a partir da qual a autorização de permanência para estrangeiros interessados em trabalhar no país foi condicionada a um contrato de trabalho. Saudado como "um sinal de amizade entre os dois países" e celebrado uma década após o primeiro caso de deportações de brasileiros na era Schengen, representou, no contexto da legislação portuguesa vigente, discriminação positiva a favor dos brasileiros. Posteriormente, em 2004, um novo processo de legalização extraordinária foi dirigido a todos imigrantes em situação indocumentada, independentemente de nacionalidade que incluiu os brasileiros. Apesar da lentidão e limites desse processo de regularização, invariavelmente denunciados pela $\mathrm{CBL}$, os brasileiros continuaram a ocupar posição superior entre os demais migrantes, acentuando as ambiguidades de suas relações com Portugal.

Essa discriminação positiva, defendida persistentemente pela CBL, já havia sido incorporada na lei de 2000, no que concerne à autorização de residência em Portugal para os trabalhadores provenientes dos países que fazem parte da Comunidade de Países de Língua Portuguesa (CPLP). Assim, enquanto os imigrantes das ex-colônias portuguesas poderiam solicitar a residência depois de viver em Portugal por seis anos consecutivos, o prazo para os demais imigrantes era de dez anos. Essa diferenciação indica a persistência de uma política portuguesa reelaborada a partir de antigas hierarquias coloniais na qual os brasileiros se situam logo após os cidadãos comunitários, são seguidos pelos

\footnotetext{
8 Ver carta na íntegra no Portal da Casa do Brasil de Lisboa: < http://www.casadobrasil.info/spip. php?article118>.
} 
demais cidadãos lusófonos e, na qual, ficam em último lugar os imigrantes extracomunitários cuja língua nativa não era o português ${ }^{9}$.

Em comparação, a lei de nacionalidade, aprovada em Portugal em 2006, de certa forma é mais completa. Além do princípio de descendência baseado no jus sanguinis, incluiu também o jus soli, especificamente para o caso de filhos de estrangeiros nascidos em território português, cujos pais não se encontram a serviço do respectivo Estado e sempre que, no momento de nascimento, um dos progenitores residisse legalmente no país pelo menos por cinco anos. Mas, apesar das afirmações do então Primeiro Ministro José Sócrates de que essa lei se fundamentava em uma "política de abertura responsável à imigração destinada à inclusão" e "integração de seus imigrantes", continuou a excluir e manter invisíveis aqueles imigrantes em situação indocumentada ${ }^{10}$.

No contexto de sua persistente militância tanto a favor dos imigrantes em Portugal como dos emigrantes do Brasil, a realização do I Encontro das Comunidades Brasileiras no Mundo em 2008 foi aparentemente resultado de uma proposta da CBL ao (então) Ministro Celso Amorim, durante uma das visitas de Lula a Portugal. Não, por acaso, essas interlocuções, iniciadas por ocasião das primeiras deportações de 1993, foram moldadas e refletem a longa experiência e práticas de governantes portugueses em relação às suas próprias populações desterritorializadas. Até a designação Comunidades Brasileiras no Mundo foi calcada na expressão Comunidades Portuguesas no Mundo relacionada à secular experiência portuguesa mundo afora. Mas enquanto as Comunidades Portuguesas no Mundo estão juridicamente amparadas pelo jus sanguinis, através da qual a nacionalidade é transmitida por descendência, no caso do Brasil, onde vigora o jus soli, as categorias Brasileiros no Exterior e Brasileiros no Mundo foram ressignificadas para afirmar o pertencimento à nação, como parte das mobilizações pelos direitos de cidadania dos emigrantes brasileiros no Brasil. Ao mesmo tempo, lideranças transmigrantes continuaram utilizando as categorias emigrantes do Brasil e imigrantes nos países onde viviam para distinguir suas mobilizações no país de origem e no país onde se radicam. Em outras circunstâncias críticas que implicavam, por exemplo, lutas por direitos de circulação em um mundo sem fronteiras, a preferência era pela categoria migrante, devido a mesma implicar no "direito de ir e vir" sem coerções. Constituem, por tanto, opções (e construções sociais) estratégicas utilizadas em situações e objetivos específicos.

Certamente, a CBL desempenhou papel pioneiro na deflagração dessa mobilização em favor de políticas públicas para as populações brasileiras

\footnotetext{
9 BAGANHA, Maria I. A cada Sul o seu Norte: dinâmicas migratórias em Portugal; MACHADO, Igor José Renó. Exclusão anunciada: reflexões sobre a nova lei de Imigração. IDEM. Reflexões antropológicas sobre as políticas de imigração e o controle de estrangeiros em Portugal.

${ }^{10}$ In "José Sócrates defende política de 'abertura responsável' à imigração". Público, 04.11.2006.
} 
desterritorializadas. No entanto, o processo pelo qual esse movimento se tornou global contou também com outros protagonistas e eventos realizados em outros contextos, como aliás reconhecido por um de seus líderes por ocasião da /l Conferência dos Brasileiros no Mundo em outubro de 2009:

Uma longa caminhada foi feita até chegarmos à presente conferência. Existem pelo menos cinco documentos que condensam dezenas de documentos de todas as partes do mundo e que devem ser valorizados: o documento de Lisboa (maio de 2002), o Documento de Boston (2005), o Documento de Bruxelas (dezembro de 2007), as conclusões da ata de consolidação de 2008 (I Conferencia dos Brasileiros no Mundo) e o Documento de Barcelona (julho de 2009).

Esses documentos dos vários encontros fazem parte de uma memória que foi sendo construída pelos próprios transmigrantes sobre esse movimento que, iniciado em Lisboa, se estendeu por cidades de vários continentes. Aparentemente, o PT investiu nessas comunidades no exterior mais do que qualquer outro partido político brasileiro. Mesmo que lentamente e em resposta às insistentes e recorrentes reivindicações, o governo Lula, em cumprimento às suas promessas de campanha, finalmente respondeu às demandas dessa população brasileira no mundo, passando a considerá-la, pelo menos retoricamente, como parte de uma propalada "democracia participativa".

\section{A globalização do Movimento dos Brasileiros no Exterior}

Concomitantemente às iniciativas da CBL, desde a década de 1990, com o aumento dos fluxos migratórios e alastramento de casos de deportações, sucederam-se mobilizações de migrantes brasileiros em cidades de vários países, passando a congregar também diferentes segmentos da sociedade civil no Brasil. Se, quando da realização de Little Brazil, primeira etnografia sobre os brasileiros em New York, publicada em 1993, Maxine Margolis havia notado a ausência de um movimento associativo, alguns anos depois começaram a proliferar associações de imigrantes brasileiros nos Estados Unidos, concentradas predominantemente no Estado de Massachusetts.

Mobilizações de ativistas e lideranças comunitárias, em sua maioria formada por profissionais liberais e acadêmicos, inclusive alguns exilados políticos, resultou em um Encontro de Lideranças Brasileiras nos Estados Unidos, na cidade de Boston em 2005, com o objetivo de estabelecer uma agenda em comum. Naquela época, havia sido instalada no Brasil uma comissão parlamentar mista de inquérito para apurar os crimes e outros delitos penais e civis praticados com a emigração em situação indocumentada de brasileiros nos EUA que resultou na visita de parlamentares a várias comunidades diaspóricas, sendo dois deles convidados para esse encontro nacional. Contando com uma conferência do Senador Edward Kennedy e presença de autoridades brasileiras 
- entre as quais o então Ministro Luiz Dulci da Secretaria da Presidência da República e fundador do PT -, essa reunião mostrou o peso dos núcleos do PT no exterior e de suas redes sociais no Brasil. Indicou também a mobilização dos brasileiros no cenário americano como um grupo étnico empenhado em se transformar em uma "minoria visível" naquele país. Conhecido como I Brazilian Summit esse encontro resultou no "Documento de Boston" contendo uma série de reivindicações ao Estado brasileiro.

Pode-se dizer que 2005 se transformou em outro marco da questão emigratória, demandando a atenção do Estado brasileiro. No mês de julho, o dramático assassinato do brasileiro Jean Charles de Menezes pela polícia de Londres, por ter sido confundido com um suposto terrorista árabe, teve grande repercussão no Brasil, trazendo à tona a vulnerabilidade dos migrantes brasileiros em situação indocumentada e a necessidade de acompanhamento permanente da política externa brasileira com respeito aos direitos humanos. Não por acaso, a ideia de criação de um Comitê Brasileiro de Direitos Humanos e Política Externa, composto por entidades não governamentais e órgãos do Estado, surgiu durante uma audiência pública sobre política externa e direitos humanos na Câmara dos Deputados, em setembro daquele mesmo ano, por iniciativa da Comissão de Direitos Humanos e Minorias. Também no espaço comunitário europeu, onde predomina o jus sanguinis (que atribui nacionalidade somente por laços de sangue e, portanto, não por nascimento em seu território), o Movimento dos Brasileirinhos Apátridas, iniciado por um jornalista brasileiro radicado na Suíça, alastrou-se via internet e conseguiu derrubar uma legislação de 1994 que proibia o registro de filhos de brasileiros nascidos fora do Brasil em repartições consulares e, que, portanto, os deixava na condição de apátridas.

Em finais de 2007, ainda no cenário europeu, lideranças do Instituto de Migrações e Direitos Humanos (IMDH), que haviam participado do I Encontro Ibérico de Brasileiros no Exterior realizado em 2002 em Lisboa, organizaram um novo encontro em Bruxelas. Ao denominá-lo II Encontro de Brasileiros e Brasileiras no Exterior - Europa, os organizadores simbolicamente retomaram o Projeto Brasileiros no Exterior que havia sido desmobilizado, com o intuito de formar uma Rede de Organizações na Europa. "Rede entendida como uma importante ferramenta de defesa dos direitos individuais e coletivos e que viria a somar-se a tantas outras valiosas iniciativas que almejam colaborar na construção de políticas públicas que assegurem condições dignas ao migrante brasileiro"11.

Destacando-se por introduzir um recorte de gênero à identidade nacional e contando com representantes brasileiros de onze países europeus (entre os quais a $\mathrm{CBL}$ ), esse encontro deu origem ao Documento de Bruxelas. Além de subscrever a Carta de Lisboa de 2002, esse documento ainda retoma e amplia

${ }_{11}$ MILESI, FANTAZZINI, op. cit. 
uma proposta de formação de rede originalmente lançada no encontro de Boston de 2005 visando unir lideranças transmigrantes dos Estados Unidos.

Mas os organizadores do encontro de Bruxelas provavelmente também seguiram recomendações do Fórum Social Mundial das Migrações (FSMM), promovido por setores ligados à Igreja Católica, que despontou em 2005 em Porto Alegre (Brasil) e cujas edições bienais desempenham importante papel na globalização de movimentos sociais em favor da questão migratória. Já em sua primeira edição, além de pregar a cidadania universal, havia a sugestão para "trabalhar em redes tendo em vista unir e articular as diversas entidades e movimentos sociais na defesa da cidadania".

Realizado através do projeto Diplomacia Parlamentar e Direitos Humanos, patrocinado pela Fundação Alexandre Gusmão, vinculada ao Ministério de Relações Exteriores do Brasil, o encontro de Bruxelas, ao articular a criação dessa rede, propiciou as condições para a mobilização política dos "Brasileiros e Brasileiras na Europa" durante a I Conferência de Brasileiros no Mundo, realizada no mesmo ano, conforme relatado e contextualizado na apresentação do Documento de Barcelona, pois se

(o) Documento de Lisboa é a base propositiva e reivindicativa do que ainda hoje não se concretizou (...), em Bruxelas, floresce o que seria a mobilização social e política para o Documento ganhar força e "sair do papel": a Rede de Brasileiras e Brasileiros na Europa. (...). De Bruxelas a Barcelona, é expressivo o diálogo que se estabelece entre a Rede e o Governo do Brasil (...). E é exatamente a participação intensa da Rede na 10 Conferência que assegura a possibilidade de constituir a principal parceria para a realização do 3o Encontro, o Encontro de Barcelona: o apoio da Organização Internacional das Migrações - OIM² .

Organizado pela Subsecretaria Geral das Comunidades de Brasileiros, o I Encontro dos Brasileiros no Mundo em julho de 2008 constituiu um ritual de reconhecimento desses transmigrantes espalhados pelo globo. Se suas remessas de divisas - que chegaram a atingir 7,5 bilhões de dólares no ano de 2007 beneficiam as localidades de onde partem e dinamizam a economia brasileira, esse reconhecimento do Estado brasileiro assinalou seus direitos de cidadania no Brasil e, portanto, legitimou sua construção social enquanto brasileiros residentes no exterior ou brasileiros no mundo.

Por quase duas décadas, recorrentes pressões junto ao Estado brasileiro, por parte de lideranças transmigrantes, organizações religiosas (especialmente às ligadas à Igreja Católica), estudiosos das migrações e outros militantes, no que tange aos direitos de nacionalidade e cidadania de "brasileiros e brasileiras residentes no exterior", tenderam a resultar, muitas vezes, somente em conquistas

${ }^{12}$ CARVALHO, Flávio. "Documento de Barcelona", p. 7-8. 
pontuais. Mas, em seu conjunto, essas diversas mobilizações, dramatizadas por prisões, crescentes deportações, mortes e até assassinatos na Europa e nos Estados Unidos de brasileiros em situação indocumentada, bem como conflitos em situações de fronteira na América do Sul, certamente influíram para que a questão migratória se tornasse foco de uma agenda intergovernamental. A realização do I Encontro dos Brasileiros no Mundo, com as reivindicações das lideranças transmigrantes consolidadas em ata, resultou na institucionalização do diálogo entre Estado brasileiro e sua diáspora e, portanto, no compromisso oficial de ações governamentais em prol de seus direitos de cidadania.

Emigrantes brasileiros, reconhecidos pelo poder público do Brasil como brasileiros no mundo, ou brasileiros residentes no exterior, passaram a fazer parte de uma pauta interministerial, que incluiu como importante protagonista, por demanda das lideranças transmigrantes, o Conselho Nacional de Imigração (CNIg) do Ministério do Trabalho. Órgão de caráter tripartite, que envolve governo, entidades sindicais e sociedade civil, com a atribuição legal para discutir e elaborar leis migratórias voltadas para o imigrante no Brasil, o CNIg também passou a formular conjuntos de ações dirigidas à diáspora brasileira ${ }^{13}$. A centralidade de questões relacionadas ao trabalho migrante, junto com discussões sobre a possibilidade desse órgão ser transformado em um Conselho Nacional de Migrações, uma recomendação feita ainda em 2007 e que consta do Documento de Bruxelas, reflete a inseparabilidade entre imigração e emigração defendida por ativistas e acadêmicos da questão migratória e, especialmente, por setores da Igreja Católica com base em sua prática com ambas populações: imigrantes e emigrantes do Brasil.

Nesse contexto, a substituição do malfadado Estatuto do Estrangeiro do tempo da ditatura militar por uma lei mais abrangente voltada às migrações e aos migrantes como sujeitos de direitos se tornou bandeira dessa articulação de movimentos sociais. Tanto a anistia concedida pelo Presidente Lula aos imigrantes em situação indocumentada no Brasil quanto sua proposta de uma nova lei migratória enviada ao Congresso Nacional (PL2655, ou Projeto Lula), ambas de 2009, foram respostas a essas mobilizações. No limiar de seu mandato, em dezembro de 2010, atendendo às demandas do Encontro de Barcelona, o Presidente Lula instituiu, através de decreto, o Conselho de Representantes de Brasileiros no Exterior (CRBE), que representou simbolicamente o final de um ciclo desse Movimento dos Brasileiros no Exterior. Em contraposição, o engavetamento do Projeto Lula (ou PL 2655/2009) no Congresso Nacional e a formulação de novos anteprojetos de lei em 2013 e 2014, num período de inversão das rotas migratórias e chegada de novos contingentes da

\footnotetext{
${ }^{13}$ Vide FELDMAN-BIANCO, op. cit., que detalha as ações do CNIg, como também de outros setores governamentais que dizem respeito aos brasileiros radicados em diversos países e continentes.
} 
África, Oriente Médio, América do Sul e Caribe, expressa a continuidade e fortalecimento dessas lutas, agora predominantemente em prol dos direitos dos imigrantes no Brasil.

\section{E a luta continua}

Essa análise demonstra a importância de uma perspectiva etnohistórica transnacional para o entendimento dos processos sócio-políticos subjacentes à constituição de um movimento social de emigrantes brasileiros por seus direitos de cidadania no Brasil, na globalização contemporânea. Através dessa abordagem, o ponto inicial na CBL permitiu delinear a mobilização de imigrantes em Lisboa por seus direitos de cidadania em Portugal desde as primeiras deportações de brasileiros da era Schengen. Ao mesmo tempo, possibilitou descrever a resultante formação, a partir da antiga metrópole imperial, de um movimento social de emigrantes brasileiros por políticas públicas em prol de seus direitos de cidadania no Brasil, num período marcado por processos de redemocratização do país.

Ambos movimentos sociais estão inter-relacionados, trazendo à tona a conexão entre migrações, nação e nacionalismo, assim como questões sobre as especificidades, ambiguidades e espaços de manobra subjacentes nas mobilizações de ex-sujeitos coloniais em antigas metrópoles imperiais. Se pressões das lideranças transmigrantes tenderam a lograr somente conquistas pontuais, na era Lula (2003-2010), as ações do governo brasileiro atenderam reivindicações que constavam da Carta de Lisboa, assim como de documentos resultantes dos demais encontros. Para além dos brasileiros da diáspora constituírem eleitorado potencial nas eleições presidenciais e suas remessas ativarem economias locais, as políticas governamentais de incorporação dessa população refletiram o processo de redemocratização do país.

Desde o início de sua luta em Lisboa pelo reconhecimento de seus direitos no Brasil, lideranças transmigrantes fizeram uso estratégico de sua identificação de pertencimento nacional enquanto Brasileiros no Exterior ou Brasileiros no Mundo, dirimindo assim, experiências diversificadas e todos os tipos de diferença de uma população diaspórica altamente heterogênea, com demandas específicas de acordo com a sua localização. Ao mesmo tempo, continuaram a utilizar estrategicamente as categorias "imigrante", "emigrante" e "migrante", de acordo com os seus posicionamentos em situações específicas.

Mas, a partir do Encontros de Bruxelas e de Barcelona, o recorte de gênero começou a subverter essas construções homogêneas, entrando finalmente na pauta de reivindicações no Encontro de Roma de 2010. Essa pauta incluía sugestões de promoção de campanhas institucionais dirigidas à desconstrução de estereótipos históricos sobre a pressuposta sensualidade e 
permissividade das mulheres brasileiras. Vale lembrar que esses estereótipos haviam sido acionados durante os conflitos diplomáticos de 1993 entre Brasil e Portugal - quando os brasileiros deportados foram referidos como mulatinha de mini-saia, vagabundos e travestis. Se, no contexto português, a reelaboração dos estereótipos está intrinsecamente ligada às antigas e ambivalentes relações entre antiga metrópole e antiga colônia, em outros países europeus também se continua a distinguir os brancos civilizados do exotismo e, por extensão, da sensualidade e permissividade racializada dos antigos sujeitos coloniais. Assim, 17 anos após as primeiras deportações de brasileiros na Europa, as conexões entre gênero, trabalho e racialização - inclusive no que se relaciona aos gays, lésbicas, bissexuais, transexuais e transgêneros - ganharam força nas mobilizações pelos direitos de cidadania no Brasil, trazendo à tona a agência de lideranças femininas e LGBT.

Mas, nessa época, no bojo da crise econômica de 2008-2009 que eclodiu na Europa e nos EUA, o Brasil, assim como outros países sul-americanos, passaram a atrair novos imigrantes. Juntamente com o retorno de brasileiros da diáspora, jovens profissionais europeus e norte-americanos foram atraídos pela oferta de trabalho em grandes projetos desenvolvimentistas. O país também passou a receber fluxos migratórios de haitianos que escaparam do terremoto de 2010, solicitantes de refúgio da África e do Oriente Médio, assim como migrantes da China e da África que se juntaram aos mais antigos contingentes de bolivianos e de outros países do continente sul-americano que começaram a afluir ainda na década de 1980, à procura de uma vida melhor. Mas, aqui chegando, esses migrantes encontram "políticas de acolhimento, mas não de acompanhamento", como tão bem resumiu o malinês Adama Konate, conselheiro eleito da Subprefeitura da Mooca, cidade de São Paulo.

Num contexto de ausência de uma legislação baseada em direitos humanos, as várias ações governamentais têm sido, em última análise, resultado de demandas das mobilizações da sociedade civil, incluindo igreja, academia e protagonizadas, cada vez mais, pelos próprios imigrantes e refugiados. Mas essas ações se tornaram insuficientes frente aos novos fluxos migratórios que chegaram ao Brasil. Apesar da constituinte de 1988 garantir direitos fundamentais, o país carece de políticas públicas. Por isso, grande parte das responsabilidades do Estado, ainda permanece no âmbito das Igrejas e ONGs.

Certamente, uma grande vitória dessas mobilizações, após uma década de lutas, foi a criação de uma Coordenação de Políticas Imigrantes na Prefeitura de São Paulo, a primeira no Brasil e o subsequente reconhecimento que esse órgão deve ser parte de uma política de Estado. Também pode ser vista como positiva a aprovação pela Comissão Especial destinada a proferir parecer ao Projeto de Lei no 2516, de 2015, do Senado Federal, que "institui a Lei de Migração", apesar da inclusão de demandas feitas por representantes da 
polícia federal (no que se refere às expulsões) e da bancada evangélica (contra o uso da categoria gênero) que deverão ainda ser discutidas em plenária do Congresso Nacional. Entrementes, num aparente paradoxo, o Brasil se alinhou à nova ordem mundial e à agenda global de combate ao tráfico de drogas, tráfico de seres humanos e contrabando. Deve-se atentar para o fato de que a adoção dessa agenda global implica em maior controle de fronteiras, tendo já resultado na aprovação, por pressão internacional, de uma lei antiterrorismo que tem o potencial de criminalizar os movimentos sociais e certos migrantes em particular. Diante desse quadro, as mobilizações em prol dos direitos dos migrantes já estão a confrontar novos desafios.

\section{Bibliografia}

BAGANHA, Maria I. A cada Sul o seu Norte: dinâmicas migratórias em Portugal. In SANTOS, Boaventura de Sousa (org.). Globalização: Fatalidade ou Utopia. Porto: Afrontamento, 2001.

BALIBAR, Étienne. We, the people of Europe. Princeton University Press, 2004.

BASSEGIO, Luiz. Reflexões a partir do Fórum Social das Migrações. 31.03.2005. Disponível em: <http://www.adital.com.br/>.

BEHR, Gustavo. Entre filas, Conselhos e maracatus. Sabiá, Lisboa, março, 2010, n. 84, p. 2.

CARVALHO, Flávio. "Documento de Barcelona". Conferência Impressa, 2009.

CASA DO BRASIL DE LISBOA. Disponível em: < http://www.casadobrasil.info/>.

CASTRO, Mary G. (org.). Migrações Internacionais: Contribuições para Políticas. Brasília: CNPD/IPEA, 2001.

FANTAZZINI, Orlando. Políticas públicas para as migrações internacionais. Disponível em: <http://www.dhnet.org.br/dados/livros/dht/livro_migracoes_ fantazzini.pdf>.

FELDMAN-BIANCO, Bela. Portuguese in Brazil, Brazilians in Portugal: Constructions of Sameness and Difference. Identities: Global Studies in Culture and Power, v. 8, n. 4, 2001, p. 607-650.

FELDMAN-BIANCO, Bela. Caminos de ciudadanía: Emigración, Movilizaciones sociales y políticas del Estado brasilero. In FELDMAN-BIANCO, Bela; RIVERA SÁNCHEZ, Liliana; STEFONI, Carolina; VILLA MARTINEZ, Marta Inés (orgs.). La construcción social del sujeto migrante en América Latina: Prácticas, representaciones y categorías. Quito: Clacso -Flacso- Universidad Alberto Hurtado, 2011, p. 235-280.

MACHADO, Igor José Renó. Exclusão anunciada: reflexões sobre a nova lei de Imigração. Revista Temáticas, Campinas, ano 8, n. 15/16, 2000, p. 147-151.

MACHADO, Igor José Renó. Reflexões antropológicas sobre as políticas de imigração e o controle de estrangeiros em Portugal. Texto apresentado na RAM, 2008 ms.

MARGOLIS, Maxine L. Little Brazil: An Ethnography of Brazilian Immigrants in New York City. Princeton: Princeton University Press, 1994. 
MILESI, Rosita; FANTAZZINI, Orlando. Cidadãs e Cidadãos Brasileiros no Exterior: O Documento de Lisboa, a Carta de Boston e o Documento de Bruxelas. Disponível em: < https://sistemas.mre.gov.br/kitweb/datafiles/BRMundo/pt-br/ file/Rosita_Milesi.pdf $>$.

MRE. Brasileiros no mundo. Disponível em: <http://www.brasileirosnomundo. itamaraty.gov.br/>.

VENTURA, Daisy. Migrar é um direito. Disponível em: < https://www.sescsp.org.br/ online/artigo/compartilhar/9732_NOVAS+MIGRACOES >.

Recebido para publicação em 20.07.2016

Aceito para publicação em 19.09.2016

Received for publication in July $20^{\text {th }}, 2016$

Accepted for publication in September 19 ${ }^{\text {th }}, 2016$

ISSN impresso 1980-8585

ISSN eletrônico 2237-9843

http://dx.doi.org/10.1590/1980-85852503880004804 